\title{
Use of Mango Seed Bio-Diesel as Diesel Fuel Extender for a Four Stroke CI Engine
}

\author{
*Pappuri Hazarathaiah ${ }^{1}$, M.Venkata Rao ${ }^{2}$, Sk. Riyaz Basha ${ }^{3}$ and Y.Ashok Kumar Reddy ${ }^{4}$ \\ Assistant Professor ${ }^{1}$, Professor $^{2}$, Assistant Professor ${ }^{3}$ and Associate Professor ${ }^{4}$ \\ Departmen of Mechanical Engineering ${ }^{1,2,3,4}$, N.B.K.R Institute of Science and Technology $y^{1,2,3,4}$ \\ *Corresponding Author Email: hazarathprk@gmail.com ${ }^{1}$
}

\begin{abstract}
Increase in crude oil price and impact of environmental pollution of increasing exhaust emission there is a need for suitable alternative fuels for diesel engine. The use of vegetable oils in CI engine results in reduces emissions compared to conventional diesel fuel. The present study covers the various aspects of biodiesels fuel derived from crude Mango Seed oil and performance, emission parameters are studied on four stroke single cylinder compression ignition engine using Mango Seed oil. Crude Mango Seed oil is converted to Mango Seed oil methyl esters by transesterification process. In the initial stage, the tests are conducted on the engine at constant speed by using diesel and base line data is generated by varying loads. In second stage, experimental investigation has been carried out on the same engine with same operating parameters by using the Mango Seed oil of methyl esters in different proportions as B5, B10,B15, and B25 to find out the performance and emissions parameters and the performance and emission parameter obtained by the above test is compared with the baseline data obtained earlier by using diesel. The blend B 15 shows better performance and reduced emission in terms of brake thermal efficiency. Results show in engine performance and emission parameters justify the potentiality of the Mango Seed oil as alternative fuel for compression ignition engine without any engine modification.
\end{abstract}

Keywords- Mango seed oil and Bio-fuel

\section{INTRODUCTION}

In the past few decades extensive use of petroleum has led to depletion of fossil fuel. Increasing human population and industrialization has led to scarcity of petroleum reserves. This has made alternate energy resources more attractive. The alternative energy resources should be renewable, sustainable, efficient and cost effective. Biodiesel is considered as one of the promising alternative resources for diesel engine, especially from non-edible oil feedstock as well as its potential to be a part of a sustainable energy mix in the future Biodiesel can be produced from non-edible seed oil like Pongamia, Karanja, Mango seed etc. These oils cannot be directly used in the engine due their high viscosity and density, and low caloric value. The glycerol component should be removed by transesterication reaction.

Biodiesels with edible and non-edible oils are widely investigated with respect to their performance, emissions and their impact on environment. Blends of biodiesel can be directly used without much alteration in existing diesel engine.

In the modern years, severe efforts have been made by many researchers to use various sources of energy as feed in existing diesel engines. Many researchers have found that biodiesel blend gives greater thermal efficiency and emission parameters. Among the different techniques accessible to reduce exhaust emissions from the diesel engine while using biodiesel, the use of ignition improvers is presently focused because of the advantage of an enhancement in fuel efficiency while reducing harmful exhaust emissions.

Water emulsified fuels are getting importance due to the simultaneous reduction of NOx and particulate matter. The addition of water in the form of emulsion has been found to improve the combustion efficiency and the brake thermal efficiency Analysis of the emissions and heat release data indicate that water enhances air fuel mixing to maintain fuel economy and lower soot emissions. The volatility difference between fuel and water enhances the micro explosion phenomenon, which leads to faster combustion reaction. There-fore, there is an improvement in brake thermal efficiency and reduction in the formation of NOx, Soot, HC and PM in the diesel engine. Usually diesel or biodiesel is immiscible with water. Surfactants are required to emulsify the fuel and ensure stability for long duration by reducing the interfacial tension. In utilizing span 80 and tween 80 in producing $\mathrm{O} / \mathrm{W} / \mathrm{O}$ three phase emulsion, 2 percent emulsifier with a $\mathrm{HLB}=6-8$ produces more stable emulsifier. Many recent papers highlight the engine performance and emission reduction in using the water emulsified diesel as fuel. Research on biodiesel emulsion is limited compared to diesel emulsion due to stability problems.

The emulsification stability of biodiesel is inferior to that of the diesel emulsion if the same surfactant mixture of span 80 and between 80 is used.

The use of vegetable oil in diesel engine is not a new concept. In fact early engines were demonstrated with veg-etable oils. In a developed country such as India where mass transportation plays a key role, the suitability of alternative fuels for a diesel fuel engine 


\section{E-ISSN: 2321-9637 \\ Available online at www.ijrat.org}

application has to be thoroughly investigated. Vegetable oils have some important properties like cetane number and calorific value similar to diesel. They have heat contents approximately 80-90 percent of diesel fuel.

Bio-diesel is not your regular vegetable oil and is not safe to swallow. However, biodiesel is considered biodegradable, so it is considered to be much less harmful to the environment. if spilled. Biodiesel also has been shown to produce lower tailpipe emissions than regular fuel. The best thing about biodiesel is that it is made from plants and animals, which are renewable resources.

Biodiesel is a clean burning renewable fuel made using natural vegetable oils and fats. Biodiesel is made through a chemical process which converts oils and fats of natural origin into fatty acid methyl esters (FAME). Biodiesel is not vegetable oil.

Biodiesel is intended to be used as a replacement for petroleum diesel fuel, or can be blended with petroleum diesel fuel in any proportion. Biodiesel does not require modifications to a diesel engine to be used. Biodiesel is simple to use, biodegradable, nontoxic, and essentially free of sulphur and aromatics.

The use of vegetable oils for engine fuels may seem in-significant in past. But such oils may become in the course of time as important as petroleum and the coal tar products of the present time.

India being a predominantly agricultural country requires major attention for the fulfillment of energy demands of a farmer. Irrigation is the bottle neck of Indian agriculture, it has to be developed on a large scale, but at the same time diesel fuel consumption must be kept to a minimum level because of the price of diesel and its scarcity. The increased use of diesel in agriculture and transportation sector has resulted in diesel crisis. Which in turn have led to an intensive search for alternative fuels. To reduce the reliance on petroleum based fuels and to reduce the emissions like $\mathrm{HC}$, CO biodiesels are gaining attention worldwide.

\section{LITERATURE REVIEW}

Many countries have been motivated to explore alternative energy sources due to increasing fossil fuel prices, energy supply security and environmental consciousness (especially related to climate change). In developed and developing coun-tries, these aspects are the main drivers to an increasing interest in biofuels. Most developed countries are moving from voluntarily to obligatory legislations to increase the market share of biofuels within the transport sector (e.g. set up of a mandatory biofuel target of 10 percent by the European Commission for the European transport sector in 2020 [1]). Bio-ethanol based on sugar and starch crops [in 2007 about 39.3 million tons $(m n t)]$ and biodiesel primarily based on vegetable oils (in 2007 about $8.3 \mathrm{mn} \mathrm{t}$ ) are currently the most common biofuels, representing, in 2007,[2] ,1.5 percent of the total fuel consumption in the transport sector worldwide [3].

However, the sustainability of an increasing biofuel use is not without controversy. In addition to the discussion on food versus fuel, it is often argued that, due to deforestation and the conversion of natural land into cropland, the negative impacts of biofuels outbalance the positive effects on global climate due to the replacement of fossil fuels[4]. Especially the significant release of greenhouse gases $(\mathrm{GHG})$ due to a conversion of primary natural forests into agricultural areas for the production of biofuel feedstock is often used to underline this argumentation [5].

This review deals with the environmental aspects of the production and use of biodiesel, analyzed with regard to the potential impact on global climate, represented here by GHG emissions. We focused on this environmental impact category, because it represents the most discussed aspect of biofuels sustainability. Furthermore, there are only few available life cycle assessment (LCA) studies that include other envi Correspondence: Mr. Stefan major, German Biomass Research Centre

The oil crops (i.e. seeds and fruits) are characterized by different specific total oil contents, e.g. in the range of 17 percent for soya beans (with soya oil as byproduct of soya meal production) to about 38 percent for rapeseeds (Table 1). For the production of oil plant [6], aspects of land use, agricultural production practice (e.g. use of fertilizer, pesticides, herbicides, fuels for machines) and harvesting (e.g. degree of mechanization) need to be considered as relevant factors for the GHG balance for the biodiesel pathway. The energetic use (e.g. as fuel for applications within the transportation sector) plays a minor but increasing role [7], using about 78 percent of the total vegetable oil production. Additionally, a further 10 percent is consumed by the oleochemical industry.

Used vegetable oils and animal fats can be applied as biodiesel feedstock, with a contribution in 2007/8 of , 10 percent to the total biodiesel production [8]. Recycled or used frying oils/ fats are common byproducts of the restaurant and food service industry. Animal fats and fish oils are by-products of the meat packing and fishery industries. Animal fats (e.g. tallow) and fish oils are recovered from animal sources by a process called rendering.

It is notable that about 50 percent of the current global biodiesel production capacity $(, 33 \mathrm{mn} \mathrm{t} / \mathrm{a}$ in 2008) is installed in Europe, where mainly rapeseed is used. About 20 percent of the globally installed capacities are found in North America and about 10 percentin Central and South America; in these countries production is mainly based on soya as raw material. Asia has about 10 percent of the total 


\section{E-ISSN: 2321-9637 \\ Available online at www.ijrat.org}

capacity, where palm fruits are the main resource. With increasing market shares, biodiesel is alsotraded on an international level, especially from the US, Indonesia, Malaysia, and Argentina to Europe.

As a raw material for biodiesel production, the crude oil from the extraction unit is initially degummed to remove phospholipids or lecithin. The phospholipids are removed since they are strong emulsifiers and can lower the yield through the acid neutralisation; they can also have an effect on the technical usefulness of the oils/fats. The second phase of refining is the neutralisation where the FFA content in the crude oil is reduced. An alkali solution (usually sodium hydroxide) is added, which reacts with the FFA to produce soaps. The soaps are insoluble in the oil and are easily separated by washing with water. Pigments and remaining traces of gums, FFA and minerals are removed by bleaching, which is done by adding specially mined clays (so-called bleaching earth) to the oil. Mostly vegetable oils are only partly refined (neutralized) because full refining is economically never compensated by the slightly lower consumption of catalyst and acid [9].

Depending on application schemes, biodiesel plants are designed in different capacity scales (e.g. from ,0.5 $\mathrm{kt} / \mathrm{a}$ to several $100 \mathrm{kt} / \mathrm{a}$ ) and performance types (e.g. batch and/or continuous biodiesel processes with or without oil mills as annex plants). The kind and quality of feedstock is the decisive factor influencing the technical design of a plant with respect to the corresponding material and energy flows. As a simplified rule, processing biodiesel in batches is more suitable for small-scale plants as simpler operating units are needed. Batch processes provide excellent opportunities for quality control if variations in feedstock quality are common, such as with grease and animal fats [10].

\section{MANGO SEED OIL}

Mangifera indica (Mango) belongs to the genus Mangifera of the family Anacardiaceae. The genus Mangifera contains several species that bear edible fruits. Most of the fruit trees that are commonly known as mangoes belong to the species Mangifera indica. Mango trees are tropical fruit bearing plants, which thrive well in Asia and Africa.

Mangifera indica is an evergreen tree in the anacardiaceaea family that grows to a height of 10$15 \mathrm{~m}$, dome shaped with dense foliage, typically heavy branched from a stout trunk. The leaves are spirally arranged on branches, linear-oblong, lanceo-late elliptical, pointed at both ends, the leaf blades mostly about $25 \mathrm{~cm}$ long and $8 \mathrm{~cm}$ wide, sometimes much larger, reddish and thinly flaccid when first formed and release an aromatic odour when crushed. The fruit is a well known large drupe, but shows a great variation in shape and size. It contains a thick yellow pulp, single seed and thick yellowish-red skin when ripe. The seed is solitary, ovoid or oblong, encased in a hard endocarp. Ripe mango fruit is considered invigorating and freshening. The juice is restorative, tonic and used as food. The seeds are usually discarded after consumption of the fleshy part of the fruits.

A Mango Tree is a large green tree, valued mainly for its fruits, both green and ripe. It can grow up to 1530 meters (4998 ft.) tall. The tree grows best in well-drained sandy loam; it does not grow well in heavy wet soils.

The optimal $\mathrm{pH}$ of the soil should be between 5.2 and 7.5. Its seeds contain an oil that has promising properties as an alternative fuel, because the mango is now cultivated in most frost-free tropical and warmer subtropical climates, almost half of the world's mangoes are cultivated in India alone, the cultivation of Mango tree is very high in India and many other tropical countries and these seeds are non-edible, therefore, the usage of Mango-seeds for oil doesnt create any shortage of edible grains and oil supply. Due to the above reasons the Mango seed oil can be alternative to the fossil fuels.

Vegetable oil from Mango Seed can also provide an effective substitute to does; as engine fuels. Mango Seed oil has a molecular structure similar to that of diesel and hence its use as fuels doesnt require any major engine modification. Mango Seed oil consist of Oleic acid (50 to 60 percent), Palmitic acid (13 to 15 percent), Stearic acid(14 to 16 percent), Linoleum acid ( 8 to 16 percent), Arachidic acid( 1 to 3 percent), it is brownish yellow oil with an acid taste and unpleasant odor. The Cetane number of Mango Seed oil was found to be around 26.The calorific value of pure Mango Seed oil was found to be around $39371 \mathrm{KJ} / \mathrm{kg}$, which is near to the calorific value of diesel( 41870 $\mathrm{KJ} / \mathrm{kg}$ ).

IV. EXTRACTION OF MANGO SEED OIL

Mango seeds were first collected from the local area and were dried for a week. The outer shell of the mango seed were then broken down after drying. Mango seeds were then crushed in local oil mill and mango oil was obtained. Mango seed oil was mixed with methanol and catalyst (potassium hydroxide) and the mixture was heated. The temperature is maintained about 60 to 70 degree Celsius. The mixture was stirred occasionally. The mixture was then kept aside for about 16 hours. The biodiesel was dried finally to be ready to use. This biodiesel is proportionally mixed with the conventional diesel to make biodiesel blends (B10, B20, B30, B40, and B50). 


\section{Available online at www.ijrat.org}

Fat is extracted from dried mango kernels by hydraulic pressure, or by solvent extraction. In solvent extraction, hex-ane, a liquid hydrocarbon, is used as the extraction medium. The collected mango stones are washed with well-water soon after collection. After washing, the seeds are sun dried to reduce the moisture content to $12-15$ percent. The dried seed stone is roasted in a drum roaster and the hull is removed mechanically, or manually by beating with wooden clubs. The separated kernels are crushed into small pieces in a hammer mill. The mango kernel pieces are conveyed to a pellet making machine and pellets are formed. The pellets are cooled to room temperature in a cooler and are conveyed to the solvent extraction plant. Some processors produce flakes by crushing the seeds in a flaking roller mill.

\section{RESULTS}

The data collected from the experiments conducted for the different percentages of Mango seed oil biodiesel, diesel blends were tabulated and respective graphs were drawn. The results from the graphs are-

Exhibit 1. Shows the variation of thermal efficiency with brake power for different Mango Seed biodiesel Diesel blends. In all those graphs thermal efficiency increases with increase in load as shown in Fig. 1

Exhibit.2. Shows the variation of exhaust gas temperature with power for different Mango Seed oilDiesel blends. The exhaust gas temperatures are decreasing incase of 20 percent Mango Seed biodiesel-diesel blend. This reveals that the energy liberation takes place during earlier part of expansion stroke, thereby reduces the energy loss in the engine exhaust as shown in Fig.??. Exhibit3. Shows the variation of fuel consumption with power produced for different Mango Seed oil- Diesel blends with the 20 percent of intervals. It is conformed that fuel consumed by the engine with 60 percent.

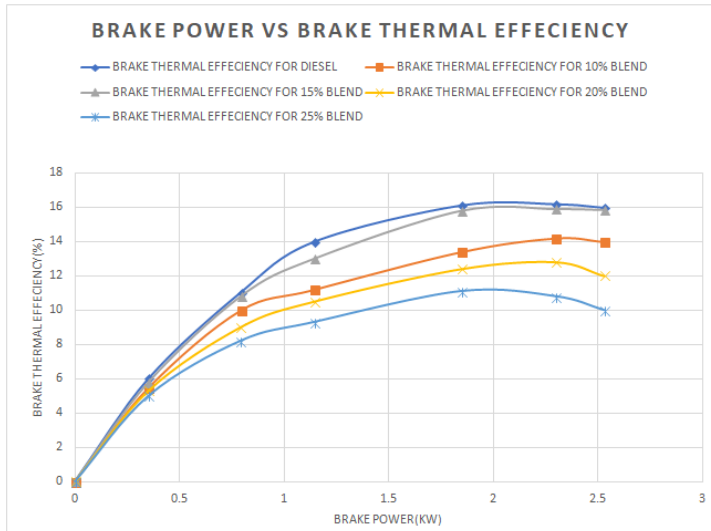

Fig. 1. Brake Power Vs Brake Thermal Effeiciency

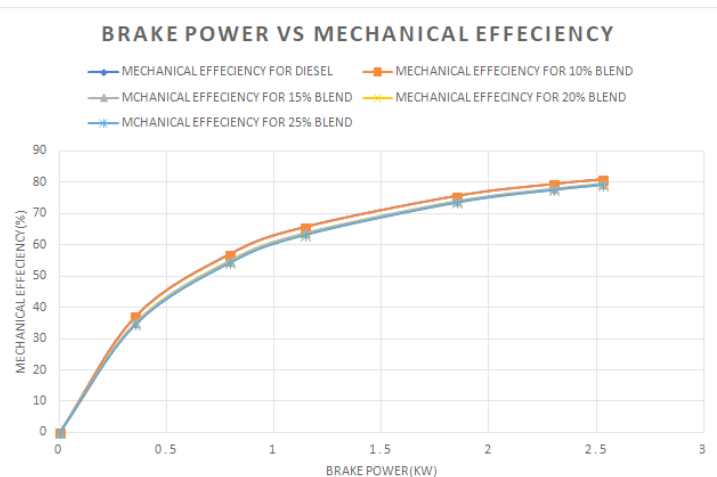

Fig. 2. Brake Power Vs Mechanical Efficiency

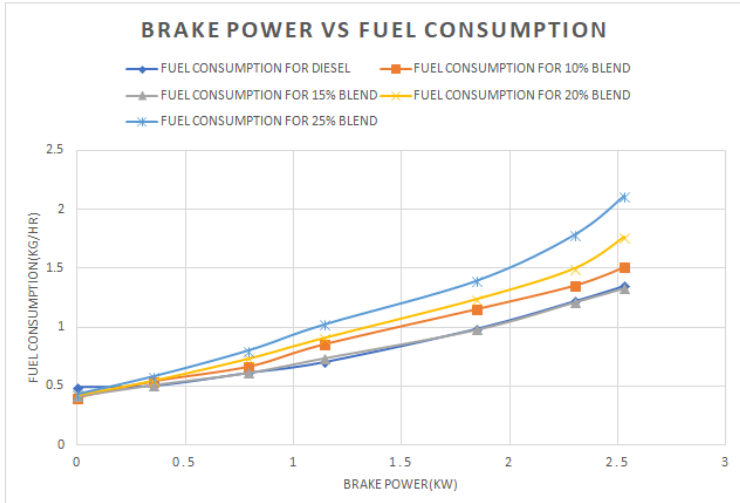

Fig. 3. Brake Power Vs Fuel Consumption

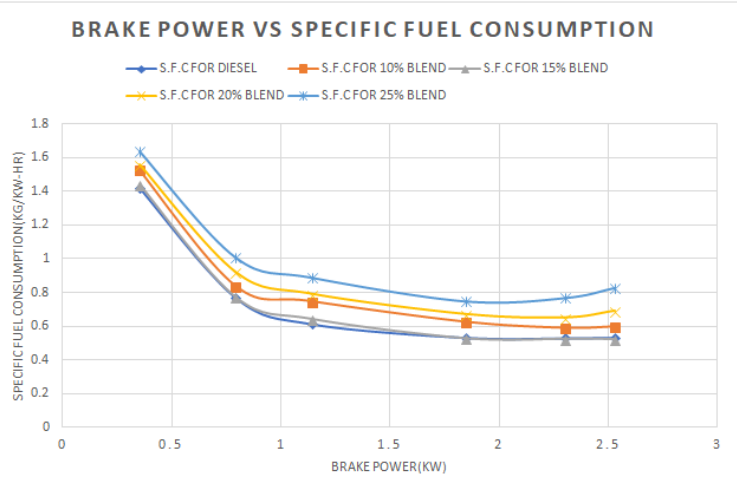

Fig.4. Brake Power Vs Specific Fuel Consumption

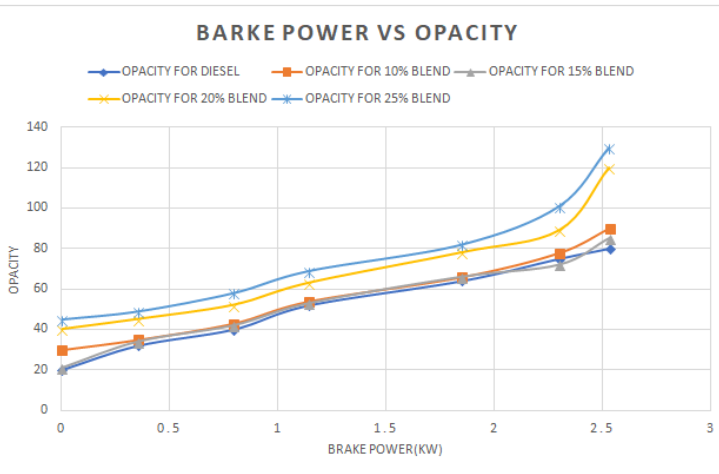

Fig. 5. Brake Power Vs Opacity 


\section{Available online at www.ijrat.org}

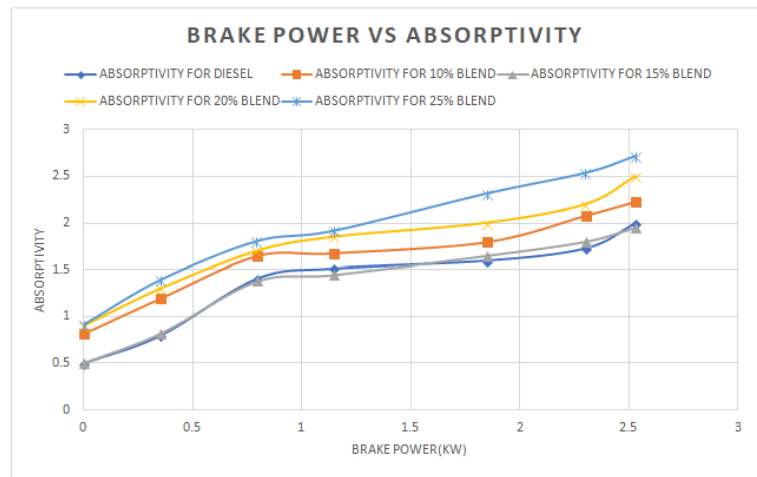

Fig. 6. Brake Power Vs Absoptivity

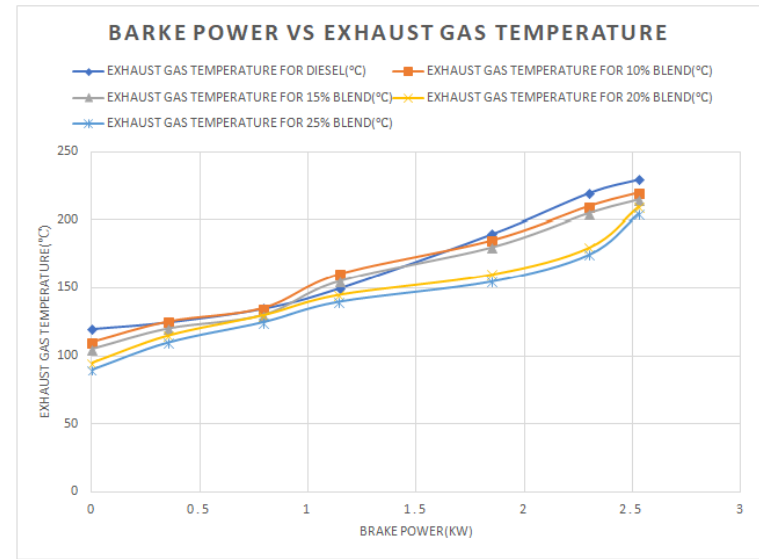

Fig. 7. Brake Power Vs Gas Temperature

\section{VI.CONCLUSIONS}

The following conclusions were made from the experiments conducted on Mango Seed oil Blends.

1. The engine runs smoothly at $10 \%, 15 \%, 20 \%, 25 \%$ biodiesel blends with diesel without any starting problem.

2. The efficiency decreases with increase of Mango Seed oil percentage and decrease of diesel percentage. 3. The parameters like SFC, thermal efficiency, opacity, absorptivity are well justified in the case of 15\% Mango Seed biodiesel and diesel blend.

4. The viscosity of the Mango Seed biodiesel is very nearer to the diesel.

5. The density of the Mango Seed biodiesel is slightly higher than the diesel.

From the above results it can be concluded that it is advantages to use $15 \%$ Mango seed oil and $85 \%$ Diesel blend without any modification for existing engine. The parameters like B.P, S.F.C, Brake Thermal Efficiency are well justified.

\section{REFERENCES}

[1] H. Haberl, D. Sprinz, M. Bonazountas, P. Cocco, Y. Desaubies, M. Henze, O. Hertel, R. K. Johnson, U. Kastrup, P. Laconte, et al., "Correcting a fundamental error in greenhouse gas accounting related to bioenergy," Energy policy, vol. 45, pp. 18-23, 2012.

[2] S. Majer, F. Mueller-Langer, V. Zeller, and M. Kaltschmitt, "Implications of biodiesel production and utilisation on global climate-a literature review," European journal of lipid science and technology, vol. 111, no. 8, pp. 747-762, 2009.

[3] J. Von Braun, The world food situtation: new driving forces and required actions. Intl Food Policy Res Inst, 2007.

[4] J. Fargione, J. Hill, D. Tilman, S. Polasky, and P. Hawthorne, "Land clearing and the biofuel carbon debt," Science, vol. 319, no. 5867, pp. 12351238, 2008.

[5] E. Gallagher and E. Gallagher, The Gallagher review of the indirect effects of biofuels production. Renewable Fuels Agency, 2008.

[6] G. W. Huber and A. Corma, "Synergien zwischen bio-und olraffinerien " bei der herstellung von biomassetreibstoffen," Angewandte Chemie, vol. 119, no. 38, pp. 7320-7338, 2007.

[7] R. F. Wilson, "Soybean: market driven research needs," in Genetics and genomics of soybean, pp. 3-15, Springer, 2008.

[8] R. E. Sims, W. Mabee, J. N. Saddler, and M. Taylor, "An overview of second generation biofuel technologies," Bioresource technology, vol. 101, no. 6, pp. 1570-1580, 2010.

[9] O. Masera, N. Rodr'iguez-Mart'inez, I. LazcanoMart'inez, L. HortaNogueira, I. Macedo, S. C. Trindade, D. Thran, O. Probst, M. Weber, " and F. Muller-Langer, "Potenciales y viabilidad del uso de bioetanol y " biodiesel para el transporte en mexico," ' Secretar'ia de Energ' 1 a, Mexico ', p. 600, 2006.

[10] U. Rashid, F. Anwar, B. R. Moser, and G. Knothe, "Moringa oleifera oil: a possible source of biodiesel," Bioresource technology, vol. 99, no. 17, pp. 8175-8179, 2008. 